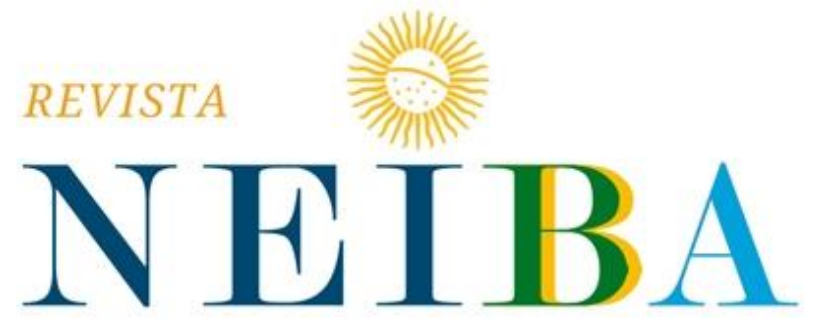

CADERNOS ARGENTINA-BRASIL

\title{
UNIVERSIDADES E INTERNACIONALIZAÇÃO DA EDUCAÇÃO SUPERIOR PARA A INTEGRAÇÃO REGIONAL: A AGENDA EDUCACIONAL MERCOSUL E AS MOBILIDADES DE ESTUDANTES BRASILEIROS PARA A ARGENTINA ${ }^{1}$
}

UNIVERSITIES AND THE INTERNATIONALIZATION OF HIGHER EDUCATION TOWARDS REGIONAL DEVELOPMENT: THE EDUCATIONAL AGENDA IN MERCOSUR AND THE STUDENT MOBILITY BETWEEN BRAZIL AND ARGENTINE

\section{Fernando Lajus ${ }^{2}$}

2Universidade Federal do Paraná (UFPR), Curitiba, PR, Brasil. E-mail: flajus07@gmail.com ORCID: https://orcid.org/0000-0003-1305-1803.

Recebido em: 04/02/2021 | Aceito em: 07/05/2021.

\section{(c) (i) \\ Esta obra está licenciada com uma Licença Creative Commons Atribuição 4.0}

\footnotetext{
${ }^{1} \mathrm{O}$ autor agradece aos(as) pareceristas pela leitura atenta e comentários proveitosos feitos ao artigo.
} 


\section{RESUMO}

A universidade tem sido uma das instituições centrais no desenvolvimento das sociedades modernas, com os últimos 30 anos vendo o surgimento de dinâmicas de internacionalização da educação superior como um imperativo para o seu progresso. Exploramos a relação deste processo com o tema da integração regional, tomando como exemplo o MERCOSUL enquanto espaço geográfico e de decisão. Para tanto, focamos nos dados que contam a história da relação entre as universidades brasileiras e argentinas desde um ponto de vista dos processos de internacionalização, em que atentamos para a existência de dinâmicas de mobilidade informais que passam despercebidas pelas estratégias de políticas de cooperação acadêmica. Discutimos como essas experiências de estudantes brasileiros na Argentina podem auxiliar na construção de uma agenda educacional no MERCOSUL que leve em conta dois pontos principais: a fatura de um sistema de acreditação comum para cursos e o incremento de programas de mobilidade científica na região.

Palavras-Chave: Internacionalização da Educação Superior; Integração Regional; MERCOSUL.

\section{ABSTRACT}

The university has been one of the central institutions in the development of modern societies, with the last 30 years seeing the emergence of internationalization of higher education as an imperative for its progress. We explore the relation of such a process with the theme of regional cooperation, taking MERCOSUL as an example of a geographical space of decision-making. We focus on the data regarding the history between the Brazilian and Argentine universities from the point of view of its process of internationalization, where we pay attention to the existence of informal dynamics that do not get into consideration in the politics of regional cooperation. We discuss how the experience of Brazilian students in Argentine can support the construction of an education agenda in MERCOSUL that takes into account two key aspects: the architecture of a common system of accreditation and the manufacturing of programs of scientific mobility in the region.

Keywords: Internationalization of Higher Education; Regional Cooperation; MERCOSUR. 


\section{INTRODUÇÃO}

As relações das universidades com o desenvolvimento de redes de mobilidades de ideias e pessoas é uma realidade histórica de longo prazo. Elas se iniciam com os peregrinadores no continente europeu durante os primeiros anos das instituições universitárias (De Wit, 2001) e chegam até os dias atuais, marcado por iniciativas estruturais entre países e blocos de países em torno da internacionalização. Atualmente, temos uma série de iniciativas rotuladas a partir do termo internacionalização da educação superior, sendo o exemplo mais sugestivo a colaboração entre universidades para a formação de uma zona de fluxo de pessoas e conhecimentos, nos moldes do Processo de Bolonha (Robertson, 2009). Não só essas iniciativas de inclusão de uma dimensão internacional nas funções e objetivos das universidades alteram essas instituições, como também esse processo pode ser efetivo para a construção de um ambiente de maior integração regional expresso em estratégias de cooperação universitária.

No artigo que segue iremos explorar esse tema da integração regional a partir da intersecção entre universidades e internacionalização da educação superior dentro do âmbito geográfico e de decisão do MERCOSUL. Nos utilizamos aqui da noção de integração regional proposta por Perrota, para quem:

[...] la integración regional tiene que ver con las interacciones económicas, sociales y culturales entre actores no gubernamentales, [...] y por el otro, la integración regional es una política pública que abarca variadas agendas temáticas o sectoriales desde una postura que se plasma en el proceso de toma de decisiones gubernamentales regionales (Perrota, 2013, p. 55).

Para tanto, dividimos o artigo em quatro outras partes além desta introdução. $\mathrm{Na}$ primeira apresentamos uma breve história das universidades, incluindo sua trajetória na Argentina e no Brasil e a emergência do processo de internacionalização como recurso das instituições para lidar com a globalização. Na segunda seção apresentamos o surgimento do MERCOSUL e de uma agenda educacional do bloco, destacando seus dois principais pontos: acreditação e mobilidades acadêmicas. Aqui também são apresentados alguns dados que compõe o quadro das mobilidades estudantis entre os dois países. 
Na terceira parte apresentamos um problema da definição clássica do estudante internacional de intercâmbio, visto que deixa de lado uma série de outras trajetórias de mobilidade internacional para a educação. Essa definição clássica dos estudantes internacionais é reflexo da maior parte da bibliografia sobre mobilidade internacional estudantil na Educação Superior (De Wit, 2001; Knight, 2003; Calvo, 2018), que aborda o processo desde o ponto de vista dos acordos institucionais que possibilitam o trânsito de estudantes entre países, em geral por tempo predeterminado de antemão. Trazemos um exemplo dentro do MERCOSUL deste outro tipo de estudante internacional e incluímos tais experiências no que chamamos de mobilidade estudantil de "baixo para cima". Tal processo faz parte de um dos eixos da internacionalização da educação superior, exatamente aquele que estimula o envio e recebimento de estudantes internacionais.

Na quarta seção apresentamos as potencialidades que esses casos das mobilidades "de cima para baixo" trazem para se propor modelos de internacionalização orientados para a integração regional. Por fim, as conclusões repassam rapidamente o apresentado de forma a dar um quadro geral das possibilidades de proposição políticas. Dessa forma, indicamos que as iniciativas informais são uma fonte significativa de informações para os projetos regionais do MERCOSUL.

\section{UNIVERSIDADES E INTERNACIONALIZAÇÃO DA EDUCAÇÃO SUPERIOR}

A universidade como instituição de ensino tem uma longa história, surgindo nos séculos XI e XII na Europa. As primeiras são as Universidade de Bolonha (1088) e a Universidade de Paris (1150), que logo espalharam seu modelo pelo continente, alcançando 73 universidades ao final de 1625 (Grendler, 2004, p.2). Na América Latina essas instituições chegam juntamente à colonização do continente. Contudo, somente a coroa espanhola veio a fundar universidades, enquanto as terras em posse lusitana cederam tais esforços a ordem jesuíta atuante por meio de seus colégios e conventos (Cunha, 2007a; Holanda, 1995).

No continente latino americano, a primeira instituição desse gênero foi a Universidade Santos Tomás de Aquino, de 1538, em Santo Domingos. No território hoje da Argentina, a Universidade de Córdoba nasceu em 1613 (Piqué, 2016). Ambas tinham um caráter religioso, funcionando como conventos para seus alunos. Seu feitio de retiro 
assemelhava-se à organização religiosa cristã, e seus conteúdos de fato eram ligados a fins teológicos. Até mesmo o estudo das línguas dos povos nativos, uma matéria lecionada em diversas universidades do império espanhol, tinha como fim a catequização dos povos indígenas na fé cristã (Tünnermann, 1996).

No Brasil, as instituições que tinham por função a provisão de educação superior para as elites ficarem em posse da Ordem Jesuíta, sendo a primeira delas construída na Bahia e mantida pelo Companhia de Jesus. Esse modelo perdurou durante a maior parte do Brasil Colônia, só sendo alterado após as reformas do Marquês de Pombal, na esteira de um processo de modernização da coroa após sua expulsão da Europa pelas forças de Napoleão. Contudo, mesmo após esse momento, não foi o modelo universitário que teve sucesso, mas sim o de Academias, como a Academia Militar e a Academia da Marinha (Cunha, 2007a).

Em ambos os países foi preciso esperar até o século XX para que as universidades tivessem uma feição mais próxima daquela que hoje conhecemos. Tanto aqui quanto na Argentina, a chegada de expressivo número de imigrantes europeus, e o êxodo rural, mobilizaram mudanças significativas nas instituições, com sua massificação e progressiva abertura para as classes médias em ascensão. Entre os anos de 1940 a 1960 vimos que em ambos os países as universidades passaram por forte processo de abertura, tal como apresentamos na tabela a seguir.

Número de matrículas na Argentina e no Brasil (1947-1965)

\begin{tabular}{|c|c|c|c|}
\hline & & \multicolumn{2}{|l|}{ País } \\
\hline & & Argentina & Brasil \\
\hline \multirow[t]{3}{*}{ Ano } & 1947 & 51.447 & 41.111 \\
\hline & 1955 & 138.000 & 72.652 \\
\hline & 1965 & 220.000 & $142.386^{*}$ \\
\hline
\end{tabular}

Em resposta a esta busca crescente por educação superior, os dois complexos universitários estruturaram estratégias diversas de provisão. No caso da Argentina, 
apesar da ingerência que os governos militares apresentaram às universidades, e também da Ley de Educación Superior de 1995 de cunho neoliberal, a provisão continuou sendo majoritariamente feita pelo setor público (Chiroleu; Suasnábar; Rovelli, 2012). No Brasil o movimento foi diverso. Já na década de 1960, durante a ditadura militar, acordos de cooperação entre Brasil e Estados Unidos (MEC-USAID) vinham propondo outras formas de organização (Cunha, 2007c). Tais projetos, materializados na lei 5.540/68, estipulavam a iniciativa privada como umas das provedoras de educação superior. Essa legislação, aliada à inexistência de universidades públicas bem estabelecidas geograficamente, estimulou o rápido surgimento de faculdades privadas isoladas, algumas, mais tarde, transformadas em universidades.

Essa diferença se apresenta em um quadro diametricamente oposto quando se trata das matrículas no ensino superior nos dois países. Enquanto no Brasil cerca de um quarto das matrículas se dá em instituições públicas (Hoper, 2018), o país vizinho apresenta cerca de um quarto de matrículas nas universidades privadas (Diu, 2018). Ou seja, enquanto no Brasil a maior parte das matrículas está nas instituições de ensino pagas, na Argentina a maior parte das matrículas encontra-se nas universidades públicas e gratuitas. Como iremos demonstrar, essa tendência brasileira tem estimulado uma série de práticas de mobilidade estudantil na América Latina, sobretudo daqueles que não podem arcar com os altos custos de certas faculdades, sobretudo na faculdade de medicina, em que uma mensalidade pode variar entre $\mathrm{R} \$ 5.000$ a $\mathrm{R} \$ 12.000$. Tal quadro coloca uma questão às iniciativas de cooperação acadêmica internacional entre os dois países, incluso dentro de âmbitos de decisão regionais como o MERCOSUL.

A internacionalização da educação superior nas universidades tem sido uma realidade constante ao menos durante os últimos 30 anos das instituições (De Wit, 2001). Esse processo tem se tornado cada vez mais um imperativo para essas instituições, tendo em vista que a globalização como conjunto de problemas (Castells, 2020; Sassen, 2010) passa a exigir delas uma inserção em dinâmicas internacionais. Como reflexo dessa crescente importância, a UNESCO, em 1998, em sua "Declaração mundial sobre a educação superior no século XXI", propõe a inclusão de práticas para desenvolver um 
ensino internacional nas universidades ${ }^{3}$. Nesse sentido, nos valemos da definição de Jane Knight, para quem a internacionalização é "[the] process of integrating an international, intercultural or global dimension into the purpose, functions or delivery of postsecondary education". (Knight, 2003, p. 2).

Diversos trabalhos têm discutido os sentidos e tendências geográficas dessas mobilidades estudantis em nível global. Se em 2010 contávamos com 4,1 milhões de estudantes internacionais (OCDE, 2012), em 2018, segundo relatório da OIM (GMDAC, $2018)^{4}$, contaríamos com um total de 258 milhões de migrantes em todo o mundo, dos quais 4,8 milhões são estudantes internacionais.

Garneau e Mazzella (2013) apontam para a desigualdade deste processo de internacionalização da educação superior. Segundo as autoras, apesar do aumento da mobilidade internacional de estudantes, estes fluxos ainda acompanham tendências geopolíticas mais amplas de prevalência de certos destinos. Se as mobilidades educacionais aumentaram, elas aumentaram sobretudo em direção aos países do NorteGlobal. Desta maneira, mais de $85 \%$ do total de estudantes estrangeiros vão em direção aos países da OCDE, dos quais dois terços são nacionais de um país não membro da OCDE. Ainda mais indicativo dessa concentração é a forma como cinco países (EUA, Reino Unido, Alemanha, França e Austrália) concentram $70 \%$ do total desses estudantes (Garneau; Mazzella, 2013, p. 185).

Desde um ponto de vista da integração regional, vale a pena perguntar quais têm sido as iniciativas para a internacionalização da educação superior na região latinoamericana, com seus desafios e potencialidades próprios (Leal; Moraes, 2018). Esses aspectos de estreitamento das relações entre universidades e países latino-americanos, descritos pela literatura como uma cooperação Sul-Sul, estão inseridos naquelas dinâmicas descritas por Perrota (2013) em sua definição de integração regional. Pode-se dizer que a cooperação acadêmica é uma das facetas de estratégias de integração na região, e ocupa uma posição importante na promoção desta agenda.

\footnotetext{
${ }^{3}$ In: Biblioteca Virtual de Direitos Humanos da USP - Declaração Mundial sobre Educação Superior no Século XXI: Visão e Ação - 1998 Direito a Educação. Sobre a internacionalização ver, em especial, os artigos 15 e 16.

${ }^{4}$ In: https://publications.iom.int/system/files/pdf/global_migration_indicators_2018.pdf. Acesso em 01/09/2020.
} 


\section{FORMAÇÃO E AGENDA EDUCACIONAL MERCOSUL}

Algumas das iniciativas de integração regional dentro das políticas de educação superior podem ser traçadas à criação do MERCOSUL como bloco de países na região. Essas iniciativas de âmbito educacional do bloco direcionam-se principalmente em dois sentidos. De um lado, trata-se da elaboração de um sistema de créditos comuns na região de forma a estimular o movimento de estudantes. De outro, busca-se construir programas de mobilidade científica entre os países partes, facilitando essa integração regional (Perrota, 2013). Ambas andam lado a lado, mas são buscadas de forma separadas nas políticas do bloco.

Tal agenda vem sendo desenvolvida desde a sua origem em 1991, com a proposição de um plano de estudo da viabilidade de um sistema de créditos comuns para as universidades proposto em 1996 (Alexsandro et al, 2018). Essa agenda também aparece em outros momentos do bloco. No programa de trabalho de $2004-2006^{5}$ a educação se faz presente nos pontos $b$ e $d$. O item b (Agenda Social) elabora uma lista de prioridade para o setor, entre elas: a circulação de mão de obra e promoção dos direitos dos trabalhadores e educação para o MERCOSUL. O item $d$ (Nova Agenda) apresenta a intenção de criação de programas de cooperação da ciência e tecnologia. Ambos os itens têm relação com políticas de internacionalização já que ocorrem via instituições de ensino e pesquisa, sobretudo as universidades, e visam incluir um aspecto internacional e intercultural em suas funções, tal qual a definição de Knight (2003).

Este movimento em torno da formação de um sistema de créditos comuns irá culminar na criação do Mecanismo Experimental de Acreditação do MERCOSUL (MEXA), implantado em 2002 e desenvolvido nos anos subsequentes. O programa de Mobilidade Acadêmica Regional em Cursos Acreditados (MARCA) opera dentro desse quadro, sendo destinado para cursos acreditados pelo Sistema de Acreditação Regional de Cursos Universitários do MERCOSUL (ARCU-SUL). O ARCU-SUL é hoje o programa e o conjunto de normas que organiza tais iniciativas de acreditação e tem por função o desenvolvimento das mobilidades de estudantes e cientistas entre universidades dos países participantes. Resultado do acordo de 2008 entre Ministros da Educação de Brasil,

\footnotetext{
${ }^{5}$ Adotado pelo Conselho do Mercado Comum na decisão no 26/03.
} 
Argentina, Uruguai, Paraguai, Bolívia e Chile, e homologado pelo Conselho do Mercado Comum do MERCOSUL, cinco são os cursos que podem buscar a participação no convênio na atualidade: agronomia, arquitetura, enfermagem, engenharia e medicina.

Apesar de tais iniciativas do MERCOSUL, temos visto nos últimos anos o afastamento de alguns atores regionais significativos, como é que o caso do atual governo brasileiro e de seu modelo de diplomacia baseado na crença de que um alinhamento automático aos EUA irá gerar crescimento econômico. Tal postura ideológica tem consequências para o prosseguimento das atividades educacionais do bloco, sobretudo quando se considera a importância do Brasil como um dos atores de maior influência na região. Por esses e outros motivos, o programa MARCA, que publicava editais anuais para proposição de projetos, não apresenta novas chamadas desde 2017, sendo 2018 o último ano de atividade dos projetos aprovados.

Parte dessa mobilidade de estudantes, pesquisadores e professores pode ser vista nos dados de internacionalização da educação superior. Exploramos os casos de Brasil e Argentina a partir da base de dados do instituto de estatística da UNESCO ${ }^{6}$. Em 2018, no Brasil, com uma população total (público e privado) no ensino superior de 8.450 .755 (Hoper, 2019), teríamos um estoque total de enviados de 58.876 e um estoque total de recebidos de 21.181 estudantes, ou seja, 0,69\% e 0,25\% do total de alunos matriculados na educação superior do país, respectivamente. Os cinco principais países de destino são EUA, Argentina, Portugal, Austrália e Alemanha, enquanto os cinco principais países de origem de estudantes internacionais no Brasil são: Angola, Colômbia, Peru, Japão e Paraguai.

Sob as informações da mesma base de dados, o caso argentino se mostra bastante diverso do brasileiro quanto a sua orientação para a internacionalização. A Argentina, com um total de 1.584.392 matriculados (Diu, 2018) na educação superior, havia enviado 9.020 estudantes para o exterior ( $0,5 \%$ do total de matrículas), sendo os principais países: EUA, Espanha, Brasil, Alemanha e França. Do lado do recebimento, foram 88.873 estudantes, 5,6\% do total das matrículas, sendo o número total quatro vezes maior que

\footnotetext{
${ }^{6}$ Para acesso às informações, ver: UIS Statistics (unesco.org) e Global Flow of Tertiary-Level Students | UNESCO UIS
} 
aquele de recebimento de estudantes internacionais no Brasil ${ }^{7}$. Os principais países de origem dos estudantes internacionais no país vizinho são: Peru, Brasil, Colômbia, Bolívia e Paraguai.

A comparação entre os dois países gera um quadro no qual o Brasil aparece com as costas viradas para América Latina e a Argentina como principal agente no recebimento de estudantes internacionais na região, colaborando para a cooperação na área da educação superior. A esse fato relacionam-se dois esclarecimentos auxiliares para a justificar o porquê da menor relevância brasileira no recebimento de estudantes internacionais. A primeira é a barreira linguística entre os países de língua espanhola e o português, e a segunda os custos da educação no Brasil. Essa última explicação se encontra ligada a já discutida divisão entre o setor público e privado, em que este último concentra a maior parte das vagas no Brasil. Se por um lado o estudo em faculdades privadas é muito caro, por outro, a entrada nas universidades públicas pelo exame vestibular torna-se uma barreira difícil de transpor, em especial para os alunos estrangeiros. Contrariamente, a universidade pública na Argentina apresenta maior capilaridade para seus postulantes, o que se expressa em maior procura por parte dos estudantes internacionais, incluindo os brasileiros.

\section{MOBILIDADES DE “BAIXO PARA CIMA" E INTEGRAÇÃO REGIONAL}

Mas qual a área de estudo busca o estudante brasileiro em mobilidade internacional na América Latina, em especial na Argentina? Via de regra, por estudantes internacionais, entendemos aqueles casos de alunos matriculados em uma universidade que farão parte de seus estudos em outra, geralmente através de acordos de cooperação ou intercâmbio. Ainda que muitos casos respeitem a essa lógica oficial, diversas mobilidades passam despercebidas por essa definição. São os casos de alunos de um país que, por conta de suas redes de contato, sejam familiares, profissionais ou de amizade, vale dizer, que detém certo capital de mobilidade (Oliveira; Kulaits, 2017), vão para outro país fazer seus estudos. São estudantes que não possuem matrícula prévia em uma instituição universitária, e que, portanto, não tem suas mobilidades viabilizadas por acordos

\footnotetext{
7 Se olharmos percentualmente a diferença será ainda maior. Percentualmente, a Argentina recebe 5,5\% mais estudantes internacionais em suas universidades.
} 
"oficiais" entre instituições. A esses casos daremos o nome de mobilidades de "baixo para cima", já que não estão contidas nos programas ou acordos formais entre universidades, ainda que os processos ocorram no interior da mesma e precisem ser organizados por elas.

Para podermos mensurar parte da distinção entre alunos "oficiais" e aqueles "informais", comparamos os dados da UNESCO de brasileiros na Argentina com os dados da CAPES de bolsistas na América Latina, inclusive na Argentina. A primeira tem maior abrangência, indicando todos os alunos brasileiros na Argentina, enquanto a segunda indica somente o caso de alunos matriculados em universidades no Brasil, mas que foram ao país vizinho cursar parte de seus estudos. Tal comparação nos auxilia em discriminar entre aqueles casos de estudantes matriculados em universidades brasileiras e aqueles que estudam na Argentina sem matrícula prévia no Brasil. A tabela a seguir mostra os cinco principais destinos de brasileiros na América Latina. Os dados da CAPES são os totais de mobilidades entre os anos de 2008 a 2019.

Principais destinos de estudantes brasileiros na América Latina

\begin{tabular}{llll}
\hline \hline & & Contagem & $\mathrm{N} \%$ da tabela \\
\hline América Latina & Argentina & 1578 & $59,1 \%$ \\
& México & 500 & $18,7 \%$ \\
& Uruguai & 216 & $8,1 \%$ \\
& Cuba & 192 & $7,2 \%$ \\
& Chile & 186 & $7,0 \%$ \\
\hline \hline
\end{tabular}

Podemos ver que a quantidade total de brasileiros na Argentina é muito menor em todo o período entre 2008-2019 que o estoque total de 2018, tal como nos mostra a UNESCO. Isso demonstra que grande parte das mobilidades estudantis entre esses dois países estão ocorrendo por outras vias que não aquelas dos acordos formais. Na maioria das vezes esse processo "informal" ocorre quando o estudante busca realizar todo o seu estudo fora do país, seja ele de graduação ou pós-graduação. Por não estar em uma universidade brasileira acaba por não aparecer nas estimativas dos órgãos educacionais 
nacionais, surgindo somente nas mensurações feitas pelos próprios países de destino ${ }^{8}$, em boletins estatísticos das universidades ou naquela de órgãos internacionais, como é o caso da UNESCO.

Diversos são os motivos que levariam estudantes brasileiros a buscar sua educação superior no exterior. Podemos citar alguns brevemente: a dificuldade de ingressar em universidades públicas por conta do exame vestibular, os altos custos de uma educação em seu país de origem, a qualidade da mesma no país de destino, projetos migratórios mais amplos, o grau de especialização que busca em certa área do conhecimento, entre outros.

Para o caso de brasileiros na Argentina, a primeira e segunda hipótese parecem ser as mais fortemente ligadas à sua migração. Isso pois o caso mais recorrente dessas mobilidades de "baixo para cima" de brasileiros para o país vizinho é aquele de estudantes na carreira de medicina. Esses se dirigem à Argentina em busca de uma educação de qualidade sem preços exorbitantes, como é o caso das universidades e faculdades privadas no Brasil. Os custos de estudos nessas instituições são muitas vezes mais altos que migrar para outros países a fim de realizarem seus estudos.

Tal processo de migração guiada por ideais educacionais tem sido aos poucos analisada em pesquisas acadêmicas, mesmo que no debate público e midiático ele já se encontre presente há anos. Em artigo recente, Angelucci e Pozzo (2020) exploraram o caso de estudantes brasileiros de medicina na Universidade de Rosário (UNR) na cidade de Rosário, situada na província de Santa Fé, cerca de 300km de Buenos Aires. Ao notarem o incremento do número de estudantes brasileiros, seguida de estratégias das universidades para organizar esse fluxo - como a recente obrigatoriedade de certificado de proficiência em espanhol de nível B2 -, as autoras analisaram o processo desde o ponto de vista da sociolinguística. Para o ano de 2017, tais estudantes brasileiros na UNR somavam um total de 2.577 estudantes, número oito vezes maior que em 2012. Segundo suas investigações, os brasileiros são aquele grupo de estudantes estrangeiros com maior crescimento na universidade em questão.

\footnotetext{
${ }^{8}$ Nesse sentido, o mais recente documento do governo argentino é de 2018, In: Síntesis de información estadísticas universitarias. Não temos conhecimento de um documento com tamanho detalhe de órgãos oficiais brasileiros. Acesso em: $23 / 04 / 2021$.
} 
Afora as bases de dados até agora apresentadas, não dispomos de outros conjuntos de dados atuais para aferir a quantidade de alunos brasileiros em todo o país na carreira específica de medicina. Na Universidade de Buenos Aires (UBA), o último levantamento do tipo foi produzido em $2011^{9}$, ainda que a resolução (CS) 904/63 estipule a realização de um censo geral a cada quatro anos. No ano de 2011, os brasileiros eram 934, ou $8.8 \%$ do total de matriculados estrangeiros, sendo em sua maior parte mulheres. Já nesse momento a carreira de medicina era a mais expressiva, com $15.3 \%^{10}$. Tomando aqui o caso da UNR e extrapolando sua dinâmica de incremento para inferir o caso da UBA, em 2017 o grupo de brasileiros chegaria a um número absoluto de 7.733 estudantes em toda a universidade.

Ainda que não tenhamos indicadores exatos, outras fontes também podem ser usadas para mensurar a relevância de tal processo. Textos jornalísticos ou matérias televisivas sobre estudantes brasileiros no país ${ }^{11}$, grupos em redes sociais ${ }^{12}$, associações de estudantes estrangeiros ${ }^{13}$, inclusive aquelas voltadas somente para brasileiros ${ }^{14}$, grupos específicos para estudantes brasileiros de medicina ${ }^{15}$, empresas de assessoria especializadas no processo de ingresso de estudantes brasileiros nas universidades argentinas, com foco específico na faculdade de medicina ${ }^{16}$. Todos esses servem de indicativos de um processo atual e constante de estudantes internacionais nessa direção, e formam o campo cujas informações se disseminam e são consumidas.

Como estudantes que ficam vários anos em outro país, muitas vezes esses sujeitos têm se definido pelo termo de migrantes. Estes estudantes/migrantes encaram uma realidade de desafios bastante diversa daquela dos estudantes internacionais convencionais, ou de intercâmbio acadêmico. As diferenças se iniciam no tempo da

\footnotetext{
${ }^{9}$ Os dados apresentados a seguir podem ser encontrados, juntamente a outros, aqui: http://www.uba.ar/institucional/censos/Estudiantes2011/estudiantes2011.pdf. Acesso em: 23/04/2021.

${ }^{10}$ Estudantes no Ciclo Básico Comum compõe a maioria. Contudo, os dados não nos indicam para qual faculdade tais alunos se dirigem depois. De toda forma, não há motivo para crer que exista uma alteração percentual significativa mesmo após a saída desses estudantes do CBC, o que manteria a medicina como principal área de estudos.

${ }^{11}$ Por exemplo, In: Estudiar afuera: Entre el desaliento y la determinación - Crónicas Migrantes (cronicasmigrantes.com). Acesso em: 23/04/2021.

12 Por exemplo, In: Aluguel para Estudantes em Buenos Aires Facebook Acesso em: 23/04/2021.

${ }^{13}$ Por exemplo, o caso da organização Estudiantes Migrantes Universidad de Buenos Aires (EsMiUBA),

${ }_{14}$ Por exemplo, a Federação Brasileira de Estudantes em Buenos Aires.

${ }^{15}$ Por exemplo, Estudantes Brasileiros de Medicina na Argentina. Acesso em: 23/04/2021.

16 Por exemplo, In: Flez Intercâmbios - Estudar Medicina na Argentina (flezintercambios.com.br), ou Interagir Intercâmbio Estudantil com Argentina (medicina-argentina.com.br). Acesso em: 23/04/2021.
} 
estada, que ao invés de ser de seis meses a um ano, passa a ser de mais tempo. Existe ainda a possibilidade de continuar no país após a formação, o que é visto por muitos como uma maneira de retribuir a educação alcançada no país vizinho.

Também encontram uma série de dificuldades que os estudantes intercambistas não estão acostumados, como é o caso da busca de vistos de permanência sem a intermediação das universidades. Além disso, se colocam outras questões, como problemas de trabalho, moradia de longo prazo, entre outras. Nesse sentido, os estudantes do processo de mobilidade de "baixo para cima", que se insere em dinâmicas de internacionalização da educação superior, encontram tanto diferentes dificuldades em suas permanências quanto também nos demonstram outras formas de se pensar a internacionalização e os caminhos para a integração regional no campo da educação superior.

\section{MODELOS DE INTEGRAÇÃO E REDES INFORMAIS}

Como já mostramos, o MERCOSUL, pelo menos em suas políticas educacionais para o ensino superior, vem apresentando certo desgaste. É indicativo disso a queda do programa MARCA, que não apresenta editais desde 2017. Entretanto, essa queda não parece ter deixado marcas permanentes nos fluxos estudantis, que do lado "oficial" sempre foram, como a comparação entre os dados da UNESCO e da CAPES demonstram, menos significativas que os fluxos de "baixo para cima". Nesse sentido, existem ainda diversos exemplos que podem ser seguidos pelos comitês do MERCOSUL para se pensar em maneiras mais oportunas de desenvolver a cooperação acadêmica. A área de medicina é uma delas, na qual encontramos uma rede já estabelecida de mobilidades estudantis mesmo sem os mecanismos de grande amplitude de acreditação regionais. Tais redes são compostas pelos grupos informais que conjugam aquelas pessoas interessadas em fazer medicina, mas que não encontram essa possibilidade no Brasil pelos motivos elencados anteriormente. Esses grupos se encontram em plataformas como: Facebook, Whatsapp, Telegram, ou ainda em páginas chaves, em redes como Instragram, Youtube, ou, também, através de empresas de assessoria.

Como uma das consequências negativas de cursar educação superior em medicina em outro país, está a necessidade de realizar exame de equivalência no Brasil pela 
plataforma Carolina Bori. O exame, descrito pelos alunos como bastante difícil, implica muitas vezes em mais alguns anos de estudos até que o estudante tenha seu diploma validado nacionalmente, levando-os a se manterem nos países de destino ou indo em direção a outro ${ }^{17}$ para exercerem suas profissões. Tal processo leva à crescente dificuldade na validação dos diplomas em universidades da região. Vale dizer, como países que fazem parte de um mesmo bloco regional (MERCOSUL), tal dificuldade implica em menor integração regional.

Em áreas como a medicina, nas quais as redes de informação para mobilidade educacional internacional já estão postas, as iniciativas oficiais poderiam se valer desses conhecimentos existentes. Ao invés de buscar construir uma organização de cooperação do zero, poderiam utilizar os conhecimentos dessas redes para alavancar a agenda regional. Esse conhecimento pode ser utilizado para explorar quais são as principais universidades de destino, qual o número de novas vagas que podem ser criadas para estudantes estrangeiros, qual tipo de parceria multilateral torna mais viável os períodos de transferência de estudantes e qual o mais adequado modelo de adequação do corpo de disciplinas para a criação de um sistema conjunto de acreditação de carreiras.

Para exemplificar, um estudo dessas redes nos levaria a entender quais são as universidades de maior procura e os motivos para tanto. Também por essa via de pesquisa, descobrimos como potencializar uma distribuição mais equitativa de estudantes entre as universidades, estimulando um crescimento homogêneo do sistema de educação superior. Para além disso, somasse a possibilidade de que, pelo exemplo dos vizinhos argentinos, o Brasil possa pensar em maneiras de estimular a vinda de estudantes argentinos para suas universidades. Essas considerações iniciais, e ainda rudimentares, no âmbito da educação superior e das práticas de internacionalização, nos levam a vislumbrar outras possibilidades de integração regional.

É, sem dúvida, um grande desafio ao MERCOSUL, tendo em vista que problemas específicos aos países do bloco podem impactar na construção de soluções conjuntas. Contudo, é também um momento de possibilidade de se pensar em novas formas de

\footnotetext{
${ }^{17}$ Em entrevistas muitos estudantes brasileiros expressam sua vontade em migrar para a Espanha após a formação na Argentina. A Espanha é um país que mantêm acordo de revalidação de diplomas de formados em universidades argentinas, o que é um atrativo para os estudantes brasileiros.
} 
integração que desenvolvam soluções próprias para a região. Essas redes poderiam ser melhor exploradas durante o processo de construção de um complexo universitário voltado, também, à questão da internacionalização da educação superior, com vistas a uma agenda de integração regional.

\section{CONCLUSÕES}

Como vimos, a história das universidades comporta trajetórias diversas, e constituise por realidades distintas. Na América Latina, com a ascensão de uma classe média imigrante, as instituições passaram por processos de expansão e consequente massificação da educação superior. Vimos também como o Brasil e a Argentina lidaram de forma diferente com esse desafio, em que o primeiro expandiu a iniciativa privada, e o segundo as universidades públicas, levando as instituições a novos desafios, como é o caso das dinâmicas de internacionalização da educação superior nos últimos 30 anos. Essa inseriu as universidades em redes internacionais, por vezes estimulando a colaboração entre países, como o caso do Processo de Bolonha e da agenda educacional no MERCOSUL.

Contudo, as iniciativas oficiais parecem não terem dado conta dos fluxos estudantis na região latino-americana. Essa internacionalização de "baixo para cima" apresenta-se como uma questão para as estratégias educacionais na região. A informalidade dessas práticas, longe de ser um empecilho para a constituição de uma agenda de cooperação no âmbito da educação superior internacional, mostra-se como um espaço de inspiração para o MERCOSUL. Temos aqui uma série de práticas que servem de exemplo para os atores institucionais do bloco, que podem aprender sobre as principais universidades de destino, os motivos da escolha migratória, as expectativas com tal estada no exterior para estudo e formas de levar adiante dois pontos centrais da agenda educacional do MERCOSUL, quais sejam, a construção de um sistema de acreditação para cursos e o fortalecimento da mobilidade internacional para cooperação entre estudantes e pesquisadores. A questão será saber se os agentes envolvidos terão a capacidade de se apresentar a este desafio e levar adiante uma agenda que coloque as relações entre os países da região como meio para o desenvolvimento das suas partes e do todo. 


\section{REFERÊNCIAS BIBLIOGRÁFICAS}

Alexsandro et al. (2018). 'A governança facilitada no MERCOSUL: transferência de políticas e integração nas áreas de educação, migração e saúde', Revista de administração pública (FGV), 52(2).

Angelucci, T. C.; Pozzo, M. I. (2020). 'Estudiantes brasileños en la facultad de ciencias médicas de Rosario (Argentina): implicancias intralingüísticas', Trabalhos de Lingüística Aplicada, 5(1).

Calvo, D. M. (2018). 'Understanding international students beyond studentification: a new class of transnational urban consumers. The example of Erasmus students in Lisbon (Portugal)', Urban Studies, 55(10).

Castells, M. (2020). A Sociedade em Rede. São Paulo: Paz e Terra.

Chiroleu, A.; Suasnábar, C.; Rovelli, L. (2012). Política universitária en la Argentina: revisando viejos legados en busca de nuevos horizontes. Buenos Aires: IEC-CONADU.

Cunha, L. A. (2007a). A universidade temporã: o ensino superior, da colônia à Era Vargas. São Paulo: Editora UNESP.

. (2007b). A universidade crítica: o ensino superior na república populista. São Paulo: Editora UNESP.

. (2007c). A universidade reformada: o golpe de 1964 e a modernização do ensino superior. São Paulo: Editora UNESP.

De Wit, H. (2001). Internationalisation of Higher Education in the United States and Europe: a historical, comparative and conceptual analisys. Tese de doutorado, Universidade de Amsterdam.

Diu. (2018). 'Síntesis de información estadísticas universitarias (2017-2018)'. Disponível em: SINTESIS IMPRESA.cdr (argentina.gob.ar). [Acesso em: 26/01/2021].

Garneau, S.; Mazzella, S. (2013). 'Présentation du Numéro: transformations des Mobilités Étudiantes Sud-Nord: approaches démographiques et sociologiques', Cahiers Québecois de Démographie, 43(2).

GMDAC (OIM). (2019). Global Migration Indicadors 2018. Berlin: Global Migration Data Analysis Centre. 
Grendler, P. F. (2004). 'The universities of the renaissance and reformation', Renaissance Quarterly, v. 57, p. 1-42.

Holanda, S. B. de. (1995). 'Cap IV: O semeador e o ladrilhador', In: Holanda, S. B. de., Raízes do Brasil. São Paulo: Companhia das Letras.

Hoper. (2019). Análise setorial da educação superior privada (encarte). Hoper Educacional.

Knight, J. (2003). 'Updating the definition of internationalization', International Higher Education, 33(1).

Leal, F.; Moraes, M. (2018a). 'Higher Education, South-South Cooperation and Brazilian Foreign Policy: analyzing the programa estudante convêncio de graduação (PEC-G)', Revista Internacional de Cooperación e Desarrollo, 5(1).

Oliveira, M. de; Kulaitis, F. (2017). 'Habitus imigrante e capital de mobilidade: a teoria de Pierre Bourdieu aplicada aos estudos migratórios', Mediações Londrina, 22(1).

Perrota, D. (2013). El regionalismo de la educación superior en el proceso de integración regional del MERCOSUR: políticas de coordinación, complementación, convergencia y armonización en las iniciativas de acreditación de la calidad de carreras de grado (19982012). Tese de Doutorado, Facultad Latinoamericana de Ciencias Sociales/Sede Académica Argentina, Buenos Aires.

Piqué, A. (2016). Políticas públicas para la democratización universitaria durante el período kichnerista (2003-2015). La experiencia de la Universidad Nacional de Avellaneda. Tese de Mestrado, Ciencias Sociales con Orientación en Educación, Facultad Latinoamericana de Ciencias Sociales/Sede Académica Argentina, Buenos Aires.

Robertson, S. L. (2009). 'O processo de Bolonha da Europa torna-se global: modelo, mercado, mobilidade, força intelectual ou estratégia para construção do Estado?', Revista brasileira de educação, 14(42).

Sassen, S. (2010). Sociologia da globalização. São Paulo: Artmed Editora.

Tünnermann, C. (1996). 'Breve historia del desarrollo de la universidad en América Latina', La educación superior en el umbral del siglo XXI, Caracas: Ed. CRESALC, pp. 11-38. 